Cuad. invest. hist. Brocarn. 17 (1991). Págs. 55-70.

\title{
SIGILOGRAFÍA DE LAS LOGIAS NORTEAMERICANAS
}

\author{
Susana Cuartero Escobés ${ }^{*}$
}

\begin{abstract}
RESUMEN.- El presente trabajo está dividido en tres partes. Las dos primeras estándedicadas al origen y significado de los principalessimbolos utilizados por las logias españolas asentadas en Estados Unidos. La tercera es un pequeño ejemplo de los sellos y cabeceras de cartas tal y como los emplearon los talleres.

SUMMARY.- The present article is separated on three parts. The two first are didicated to origin and significated of the principalsymbols used by the spanishlodges established in United States. The third is a small example of this stamps and lettersheads such us they were utilized by the workshops.
\end{abstract}

Palabras clave: Sigilografía, Masonería, Simbolismo, Estados Unidos, Iconografía.

Key words: Sigilography, Masonry, Symbolism, United States, Inconography.

En las siguientes páginas vamos a intentar explicar las características principales de algunos sellos y membretes que utilizaron las logias norteamericanas, sin olvidar que no fueron éstas sus únicas manifestaciones artísticas.

El período cronólogico que abarcaremos es el comprendido entre los años 1893, momento en el que varias logias norteamericanas entran en la Federación del Grande Oriente Español, y 1922, fecha en que se separan esas logias que durante más de treinta años dependieron de Madrid.

\section{LOS SIMBBOLOS Y SUS ORIGENES}

Mucho se ha escrito y especulado sobre el origen de la Masonería. Es esta una cuestión que podría llevarnos muy lejos debido al aura mítica y a las genealogías

\footnotetext{
*Universidad de Zaragoza.
} 


\section{SUSANA CUARTERO ESCOBÉS}

fantásticas con que algunos, en muchas ocasiones los propios masones, la han querido relacionar $^{1}$. Por este motivo partiremos del hecho cierto y mayoritariamente aceptado de que la masonería desciende directamente de asociaciones y corporaciones gremiales de canteros, picapedreros, ... constructores, en definitiva, de la Edad Media ${ }^{2}$.

Fue este un largo lapso de tiempo en la historia de Europa. Muchos e importantes cambios se operaron en él y si alguno, en mi opinión, merece ser destacado por encima de los demás, es el periodo gótico. El espiritualismo religioso dio paso a un mundo más terreno, más cercano al hombre. Los monasterios fueron sustituidos por las ciudades en donde se concentraron la riqueza y el poder de comerciantes, artesanos y agricultores libres. La catedral, sobre todo, se va a erigir como símbolo de estas ciudades. Unos aportan la mano de obra, otros el arte y muchos el dinero. Todos quieren contribuir a su edificación. Así es como adquirieron gran desarrollo los gremios relacionados, en mayor o menor medida, con la construcción, los denominados masones operativos.

Varios factores hicieron que esa masonería operativa decayera: el paso del tiempo, la carestía de las obras, el nuevo concepto de ciudad y de urbanismo... Es el período de transición. Algo confuso y, desde luego, peor conocido que los otros dos, .el de la masonería operativa y el de la especulativa. Como recoge el profesor Ferrer Benimeli este proceso puede seguirse a través de la St. Mary's Chapel Lodge, de Edimburgo y de la Logia madre de Kilwinning ${ }^{3}$.

A pesar de ello, las asociaciones «atravesaron toda la Edad Media, y llegaron a

ncipios del siglo XVIII habiendo conservado sus tradiciones, su ritual, su simbolismo, sus palabras y contraseñas tactiles, permitiendo a los miembros el reconocerse y ayudarse» ${ }^{4}$. Llegamos así a 1717 , año en que comienza como tal la masonería especulativa, ya completamente desvinculada del oficio de la arquitectura.

Retomaremos ahora al caso norteamericano. Al intentar trasladar todo lo anterior a Estados Unidos, el esquema falla. La masonería llegó a aquel país por vía inglesa, en las últimas décadas del siglo XVII o en los primeros años del siglo XVIII. Esto la sitúa en pleno periodo de transición y nos pone de manifiesto la carencia del Royal Craft o del Royal Art en aquel pais 5 .

Durante estos años, y hasta muy avanzado el siglo XVIII, los masones tuvieron su lugar de reunión en las tabernas. En Estados Unidos, por cierto, con mayor motivo, pues no

1 Algunos la relacionan con Salomón, otros con la Orden del Temple, con los misterios de Egipto y Persia, con los druidas, los luciferinos, etc., Ferrer Benimeli, J. A., Masonería, Iglesia e Ilustración, Fundación Universitaria Española, Madrid, 1977, vol. I, p. 23.

2 Según un estudio realizado por Ch. Bernardin, en 206 obras consultadas sobre el origen de la masonería hubo 39 opiniones distintas, de ellas la primera es la que atribuye el origen a «los albañiles constructores del periodo góticon. Ferrer Benimeli, J. A. Masoneria, Iglesia e Ilustración, p. 24, y Mellor, A., La Masonería, A.H.R., Barcelona, 1968, p. 25-26.

3 Ferrer Benimeli, J. A., La Masonería española en el siglo XVIII, p. 24.

4 Ferrer Benimel, J. A., Masoneria, Iglesia e Ilustración, p.26.

5 «el período de transición abarca fundamentalmente de $1660 \mathrm{a} 1716 »$. (Findel, apud Ferrer Bemimel, J. A. Masonería, Iglesia e Ilustración, p. 52). Para Mellor se sitúa, más ambiguamente entre los siglos XVI y XVII, «cuando el ideal constructivo se torna ideal espiritual». (Mellor, A., «El arte masónico y sus símbolos» en Historia 16, p. 30). 


\section{SIGILOGRAFIA DE LAS LOGIAS NORTEAMERICANAS}

llegaron a conocer las logias como tales, como lugares de reunión y trabajo de las corporaciones medievales 6 .

$\mathrm{El}$ aspecto tétrico, lúgubre y sombrío de estos lugares favorecía cualquier cosa menos la inspiración arquitectónica y daba pie a todo tipo de conjeturas y presunciones sobre las ceremonias rituálicas que alli tenían lugar. Pero las tabernas, no fueron exclusivamente americanas. Ya Stephen Jones recoge en 1811 una lista de 621 logias que tenían sus sesiones en ellas ${ }^{7}$. De esas 621 , al menos veinticuatro estaban en Estados Unidos, repartidas entre los estados de Nueva Inglaterra, Carolina del Sur, Virginia y Georgia.

Conforme pasaron los años la situación cambió. Comenzaron a levantarse los templos tal y como han llegado hasta nuestros días Naturalmente, la expansión de la masonería por los principales centros económicos americanos: Philadelphia, Boston, New York... y el incremento de sus miembros, están íntimamente relacionados con el hecho. En el siglo XIX, por ejemplo, encontramos ya importantes construcciones de las que destaca el New Masonic Hall, dedicado al Gran Arquitecto del Universo el 5 de septiembre de 1855. Es este templo un perfecto ejemplo del revival arquitectónico, en voga en este momento, una clara rememoración del pasado masónico, para entonces ya lejano. Una vuelta, en fin, a los orígenes de la masonería: al gótico.

\section{PRINCIPALES SÍMBOLOS Y SU SIGNIFICADO}

De todos es sabido que si algunos útiles de trabajo se relacionan con la Masonería estos son los pertenecientes al gremio de la albañilería. Durante la Edad Media, como apunta el profesor Ferrer Benimeli, «la representación emblemática de los útiles masónicos no sólo revestía el carácter de la época, sino también una prueba de las relaciones morales directas entre los asociados, no siendo los picapedreros sus inventores, aunque éstos les atribuyeran un valor de santidad»" ${ }^{8}$. O lo que es lo mismo: las herramientas se cargaron de contenido simbólico durante el periodo operativo y, sobre todo, durante el de transición, debido a las características morales y religiosas que imperaban en la época.

Así, podemos afirmar que al mutismo sobre los secretos técnicos propios del oficio de maçon, como por ejemplo «el de la estabilidad de un arco», se fue añadiendo otro tipo de enseñanza, de orden esotérico, que acabó por predominar.

Por este motivo, cuando entra la masonería en Estados Unidos, lo hace no reproduciendo algo material, como podía ser una catedral gótica, sino haciendo visible algo que no lo es, las ideas que subyacen bajo la representación gráfica de un compás, una escuadra o una rama de acacia. Símbolos, en definitiva, llenos de ese esoterismo mencionado antes y que significaría, por encima de otras interpretaciones, la enseñanza dada a los discípulos ya

6 Recordemos que la logia se situaba a un lado del edificio en construcción, generalmente en el norte y con orientación este-oeste. Al no haber masonería operativa en Estados Unidos, desconocían el auténtico valor de la logia.

7 Jones, S., Masonic Miscellanies, Vernor Hood \& Sharpe, London, 1811.

8 Ferrer Benimel, J. A., Masonería, Iglesia e Ilustración, p. 39. 


\section{SUSANA CUARTERO ESCOBÉS}

instruidos en un tipo de pensamiento comprometido con determinadas ideas. La masonería se benefició con esto porque obligó a no admitir aprendices que no reunieran las condiciones necesarias como para entender el lenguaje simbólico.

El simbolismo pasa a convertirse así en el nexo de unión entre la masonería operativa y la especulativa.

¿Cuáles eran esos símbolos y qué representaban?. Estas son las dos cuestiones que abordaremos ahora.

Todo símbolo expresa una idea. Tal y como lo define el Diccionario Enciclopédico de la Masonería, símbolo es «un signo externo y visible con el que se enlaza un sentimiento espiritual, una emoción o una idea» ${ }^{9}$.

Son muchos los símbolos asociados a la masonería; en ocasiones con orígenes diferentes (las columnas tienen origen bíblico mientras que la escuadra procede de la construcción), pero complementarios entre sí. Como hemos observado que los más repetidos en las logias americanas son los referentes a la construcción, tanto en la versión de arquitecto (escuadra y compás), como en la de albañil (paletas y plomadas), será a ellos a los que nos dedicaremos con mayor atención.

Escuadra: compuesta por dos líneas perpendiculares y simétricas simboliza; para Boucher, la equidad ${ }^{10}$; para Frau, la rectitud ${ }^{11}$; para Ambelaine, la cualidad esencial sería la inteligencia ${ }^{12}$.

Parece que el significado más acertado es el de eqité en el sentido de equilibrio, pues es la resultante de unir un elemento activo con otro pasivo, lo que automáticamente la convierte en algo estático, equilibrado. Una de las constantes en el simbolismo masónico es la coincidencia de contrarios, la atracción de los polos opuestos.

Con la escuadra se trazan los cuadros que componen el cubo, la piedra cúbica perfectamente tallada y opuesta a la piedra bruta. Símbolos ambos del hombre después de la iniciación y antes, respectivamente. La escuadra es el elemento que significa la materialidad, el apego del hombre al espacio terrenal.

Está presente en toda ceremonia de masonería simbólica, es decir, en los grados de aprendiz, compañero y maestro. Los dos primeros la utilizan como signo de reconocimiento y en los pasos de la marcha. En el tercero, su mayor importancia radica en el golpe mortal que dio el segundo compañero a su maestro Hiram ${ }^{13}$.

La escuadra no aparece nunca sola. Necesita complementarse con otro elemento que sea móvil, como el compás.

Compás: formado por dos brazos articulados y empleado para trazar círculos y medir. Como la rueda, es uno de los utensilios más antiguos que creó el hombre. Para Boucher aparece asociado a la idea de espíritu, de divinidad ${ }^{14}$; para Frau significaría la justicia con

9 Frau, L., Diccionario Enciclopédico de la Masonería, vol. 3, p. 1835.

10 Boucher, J., La Symbolique Maçonnique, Deruy, Paris, 1968, p. 1.

11 Frau, L., Diccionario Enciclopédico de la Masonería, vol. I, p. 423.

12 Ambelaine, R., La Symbolique des outils dans L'Art Royal, Editions du Prisme, Paris, 1975.

13 Ferrer Benimel, J. A., Masonería Iglesia e Ilustración, p. 27.

14 Boucher, J., La Symbolique Maçonnique...., p. 6. 


\section{SIGILOGRAFIA DE LAS LOGIAS NORTEAMERICANAS}

que deben medirse los actos de los hombres ${ }^{15}$, mientras que para Ambelaine, la facultad esencial seria la integridad ${ }^{16}$.

Es un instrumento móvil y por lo tanto activo, lo que hace que su asociación con la escuadra sea perfecta. Se complementan, queriendo significar la unión «suelo-tierramateria» con «cúpula-cielo-divino-espíritu»17.

Aunque es habitual, como más tarde veremos, que aparezcan juntos, no siempre lo hacen de la misma forma. Así, como recoge Boucher podemos encontrar el compás abierto a $45^{\circ}, 60^{\circ}$ o $90^{\circ 18}$. Ello viene a representar el camino que debe recorrerse para llegar a la perfección, o dicho de otro modo, se pasa de un incompleto dominio de la materialidad $\left(45^{\circ}\right.$ ), al equilibrio entre la materia (la escuadra cuyo ángulo son $90^{\circ}$ ) y el espíritu (el compás abierto también a $90^{\circ}$ ).

También puede aparecer la escuadra sobre el compás, la escuadra y el compás entrelazados, y el compás sobre la escuadra. Esto es; la materia domina al espíritu (aprendiz); las fuerzas se equilibran (compañero) y el espíritu trasciende a la materia (maestro).

Cincel y mallete: nuevamente encontramos asociados un elemento pasivo y otro activo. Según Ambelaine la facultad esencial del cincel sería la piedad, mientras que la del mallete sería el miedo ${ }^{19}$. Ambos aparecen asociados al grado de compañero pues son los instrumentos utilizados para desbastar la piedra.

El mallete equivaldría a la fuerza y el cincel a la belleza.. Sin los golpes que dirigen al mallete, el cincel no podría crear una obra bella.

Nivel y plomada: sabiduría y fuerza respectivamente ${ }^{20}$. Horizontalidad y verticalidad..Elemento pasivo el primero, elemento activo la segunda. Dos opuestos otra vez, símbolos de la igualdad y de la rectitud y la justicia, para Frau ${ }^{21}$.

Regla y palanca: para Ambelaine irán asociados a la gracia y al coraje $\mathrm{e}^{22}$, mientras que Boucher y Frau coinciden en que la regla es el símbolo de la perfección, y la palanca el de la fuerza ${ }^{23}$. En este caso, la regla sería la herramienta activa y la palanca la pasiva. Ambos son característicos del grado de compañero ${ }^{24}$.

La regla solía estar dividida en veinticuatro partes, equivalentes a las horas del día y recordaba al masón la necesidad de trabajar y repartir el tiempo a lo largo de ellas.

Paleta o trulla: este útil es diferente a los anteriores. No es ni activo ni pasivo, es neutro. Se le considera Símbolo de la fraternidad universal, de la tolerancia y la indulgencia.

Naturalmente no son éstos los únicos símbolos pero sí los más característicos e importantes.

15 Frau, L., Diccionario Enciclopédico...vol.I, p. 304

16 Ambelaine, R., La symbolique des outils...

17 Leveder, R., La Francmasonería vista por dentro, ediciones Obelisco, Barcelona, 1987.

18 Boucher, J., La Symboilique maçonique..., p.7-8.

19 Ambelaine, R., La Symbolique des outils...

20 Ambelaine, R., La Symbolique des outils...

21 Frau, L., Diccionario.Enciclopédico.., vol. III, p. 886.

22 Ambelaine, R., La Symbolique desoutils.

23 Boucher, J., La Symbolique Maçonique..., p.19; Frau, L. Diccionario Enciclopédico..., vol. III, p. 1016.

24 La regla se utiliza en el segundo, tercer y cuarto viaje del compañero mientras que la palanca sólo se usa en el segundo. La regla, además, aparece en el grado de maestro por ser el primer instrumento que golpeó e hirió a Hiram. 


\section{SUSANA CUARTERO ESCOBES}

\section{LA ICONOGRAFLA Y SU ESPACIO}

Los elementos iconográficos arriba descritos, van a tener un destacado papel en todo tipo de actividad masónica. Así, los encontramos en diferentes sitios:

- en el templo y en la logia;

- en sellos y cuños;

- en membretes y cabeceras de cartas;

- en diplomas y cuadros de oficiales ${ }^{25}$.

\section{El templo y la logia}

El templo es el lugar donde los masones centralizan su actividad, de ahí que su importancia sea incuestionable. Lo normal hubiera sido que cada logia dispusiera de uno pero, las dificultades económicas por las que en ocasiones atravesaban, impedía que el templo fuera un edificio entero (la mayoría de las veces tenían que conformarse con una habitación). Este fue el caso de las logias que dependian de España.

Como contrapartida, otras obediencias rivales sí que los erigieron Es el caso de la Gran Logia de Masones Libres y Aceptados de Pennsylvania. Su actual templo, dedicado en 1873, consta de siete salas perfectamerite deçoradas en diferentes estilos: jónico, corintio, renacentista italiano, normando, gótico, oriental y egipcio. Además de la biblioteca, el museo y la sala de banquetes Incidiremos en la idea de que este templo nunca perteneció a España.

La que sí dependía de Madrid era la Gran Logia Regional de Philadelphia cuya fotografía encontramos en el Archivo Histórico Nacional de Salamanca ${ }^{26}$. En ella vemos concentrado todo el simbolismo masónico.

En primer término vemos dos grandes columnas. Proceden del pasaje bíblico de la construcción del Templo de Salomón, adoptado por muchos como origen de la masonería y base de algunas ceremonias rituálicas ${ }^{27}$. Las columnas colocadas a la entrada del mismo eran de cobre y fueron denominadas por Hiram, arquitecto-decorador del citado templo Yakin y Boaz situándose a derecha e izquierda, respectivamente.

Vendrían a simbolizar la estabilidad y la firmeza sobre las que debe asentarse la construcción. En este caso la construcción no es otra que el gran edificio de la fraternidad universal. Este concepto está representado en las esferas que apoyan sobre los capiteles corintios que rematan las columnas.

En el centro de la sala , y elevado sobre una tarima triangular, se halla el altar. Como muy bien lo describe Frau, es la «mesa consagrada por los francmasones para recibir los

25 También aparecen en mandiles, collarines y joyas, pero como no hemos encontrado ninguno de estas logias, los omitiremos.

26 A.H.N.S., LEG 294-A.

27 En la del grado de maestro, por ejemplo, se representa simbólicamente la muerte de Hiram a manos de tres de sus obreros. 
SIGILOGRAFIA DE LAS LOGIAS NORTEAMERICANAS

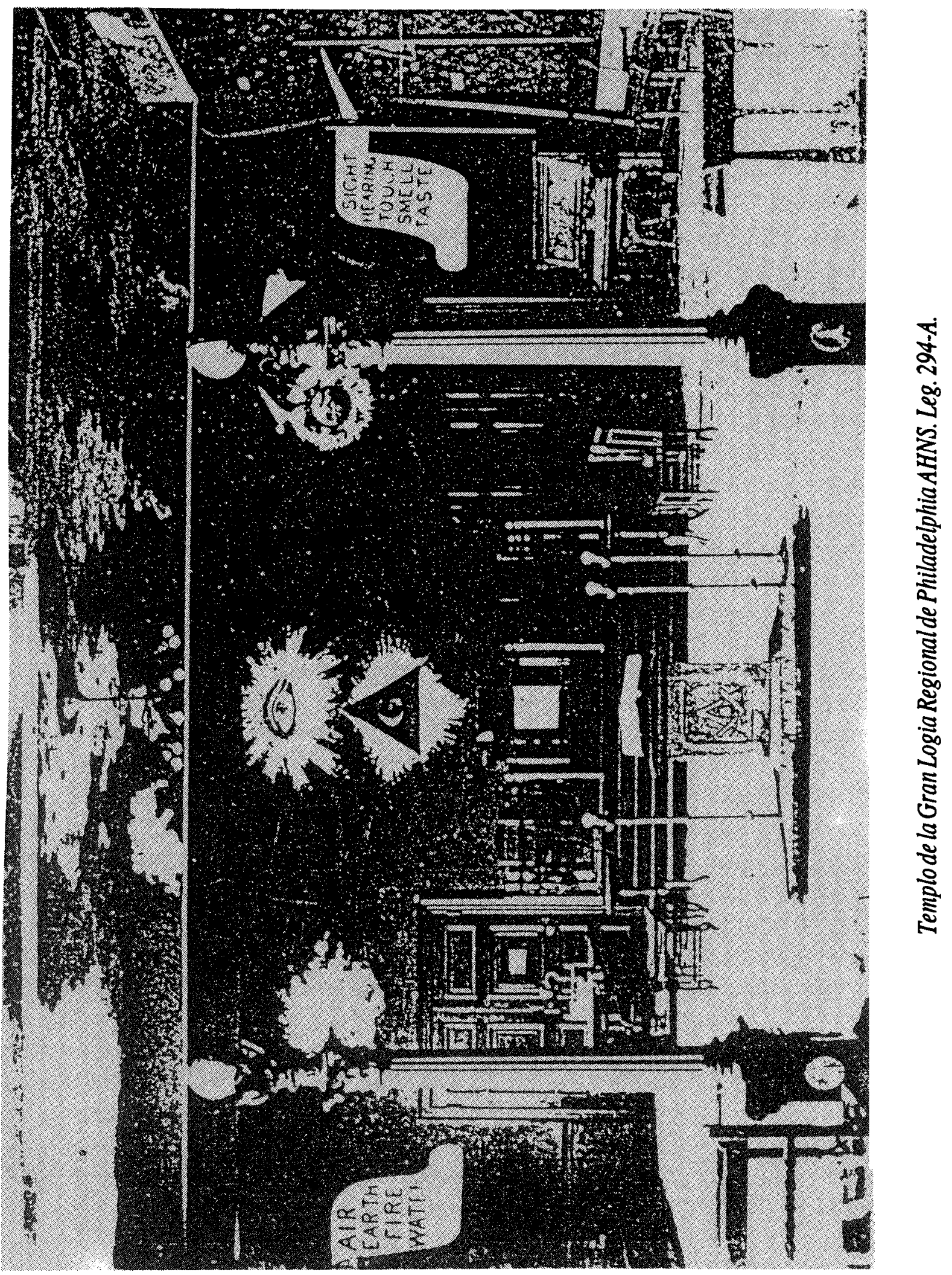




\section{SUSANA CUARTERO ESCOBÉS}

juramentos y depositar en ella el libro de la ley y los atributos del grado en que se celebran las sesiones» ${ }^{28}$.

El libro de la Ley podía ser cualquier libro sagrado. El pie del altar lleva grabadas la escuadra y el compás, los signos más característicos de la masonería.

En la misma tarima, y alrededor del altar, se sitúan tres velas en un soporte de pie. Su significado: sabiduría, fuerza y belleza. Si trasladamos esta trilogía a la mitología griega, por ejemplo, la encontramos representada en los dioses Zeus, Apolo y Afrodita. Por otra parte, el número tres es el número perfecto. Hace referencia a la armonía.

Al fondo de la sala, en el Oriente, y tras subir cinco peldaños ${ }^{29}$ vemos los sillones correspondientes al Primer y Segundo Vigilante (derecha e izquierda, respectivamente).Elevado sobre otro pequeño podio de tres escaleras, la mesa y el trono del venerable.

Enmarcando el sitio de honor se encuentran los asientos del resto de los oficiales de la logia. Observamos que en la esquina izquierda hay un piano lo que nos hace pensar que había algún «hermano» encargado de interpretar las marchas, los himnos, las canciones...

Las paredes están decoradas con diversas representaciones cosmológicas. Justo encima del sillón del Venerable, el delta místico con la «G» en su interior. Encima del mismo, el ojo de la divinidad. Para algunos, el delta guarda la palabra divina. En muchas ocasiones figura la letra "G» en medio, lo que ha hecho que se le atribuya un valor especial. Existen diversas interpretaciones sobre el significado de dicha letra, sin embargo, el más aceptado es que es el monograma de los nombres del Ser Supremo: God (Dios).

El ojo es el emblema del Gran Arquitecto del Universo. Tanto él (el ojo) como el delta están rodeados de los rayos luminosos.

A derecha e izquierda están pintados el sol y la luna, astros identificados con el día y la noche, la luz y la tiniebla; siempre antitéticos para complementarse.

El techo forma la bóveda celeste y como tal aparece pintado.Hay algunas nubes, pero el predominio del color azul disipa la tiniebla y hace que todo resplandezca con la Luz.

Finalmente, en ambas esquinas hay, a modo de carteles, dos pergaminos con las leyendas:

- «air, earth, fire, water», en el de la derecha;

- «sight, hearing, touch, smell, taste», en el de la izquierda.

Obviamente el primero son los cuatro elementos que forman la tierra, aire, fuego, tierra y agua, y el segundo, los cinco sentidos: vista, oído, tacto, olfato y gusto. Todos directamente implicados en las ceremonias de iniciación. Recordemos que toda ceremonia iniciática implica la regeneración del hombre para sustituir sus viejos vicios y pasiones por otras virtudes. Para ello es necesario someterse a una serie de pruebas, más morales que físicas, en las que entran en juego todos los elementos.

\section{Sellos y cuños}

Este tipo de representaciones plásticas, artes decorativas o artes menores, son, con frecuencia, subestimadas por considerarse de menor categoría estética. 


\section{SIGILOGRAFIA DE LAS LOGIAS NORTEAMERICANAS}

Para cualquiera que se acerque a un documento, los sellos pueden parecer simples ilustraciones. Sin embargo, estaban llenos de contenido pues, como expresa Rene Hyughe, cuando el hombre concibe su arte lo hace de acuerdo con su noción del mundo, sus aspiraciones y sus condiciones de existencia. O lo que es lo mismo, si a cada signo se le dio un valor determinado durante el tiempo de los masones operativos, y representa, por tanto, una idea, la plasmación de varios de esos signos en un sello dará lugar al concepto o conceptos que se quieren destacar.

Según el Diccionario Enciclopédico de la Masonería en su voz sello, éste es un «utensilio de metal o de cualquier otra materia, en que están grabados el título y los atributos particulares y distintivos adoptados por las Logias, Grandes Logias, Grandes Orientes, etc. y que éstas imprimen en todos los documentos oficiales a fin de revestirlos de mayor autenticidad) ${ }^{30}$.

Los sellos son la representación simbólica de una colectividad; la de los hombres que componen la logia. La función principal de éstos útiles es la de satisfacer una necesidad administrativo-burocrática ${ }^{31}$.

Se estampaban sistemáticamente tanto sobre la correspondencia como sobre documentos y diplomas, según Lobreau ${ }^{32}$ para:

- antes de la utilización de los sobres. se sellaban los dos extremos opuestos de la carta con el fin de dar carácter inviolable al texto;

- autentificar el texto, las firmas y el origen del documento;

- afirmar la autoridad o la competencia de los firmantes .

Así pues, dado que todo papel sellado automáticamente adquiría valor oficial, se requirió de una persona que se encargara exclusivamente de guardar los cuños. Este era el Guarda-Sellos, uno de los dignatarios que no podían faltar en la logia.. En ocasiones coincidia con el cargo de Secretario.

Cada logia disponía de varios sellos desde el mismo momento de su constitución, susceptibles de ser cambiados o remodelados. Las características comunes a todos los sellos eran:

- por su creación y procedencia, los sellos son pequeñas obras de arte culto pues se necesita una iniciación y un aprendizaje para comprender el simbolismo;

- el material era cera, metal o caucho;

- se desconoce el autor, no aparecen firmados ni conservamos ningún documento que nos de pistas sobre ello;

- los motivos decorativos son, por una parte, epigráficos, vegetales, geométricos y, por otra, los puramente masónicos: los útiles de construcción.

- los sellos pueden analizarse aisladamente, pero están totalmente vinculados con el marco, la logia, para el que fueron creados;

- su creación tiene un condicionante de tipo interno muy claro: los propios útiles de albañilería, por ejemplo, crean una estética determinada. Esta, a su vez, sugiere los motivos decorativos;

30 Frau, L., Diccionario...Enciclopédico, vol. III, p. 1819.

31 En este sentido podriamos denominarlos arte útil más que decorativa.

32 Lobreau, D. P., Franc-Maçonnerie \& Sociétés Secrétes á Beaune et Bourgogne (1760-1940), Lodi, Paris, 1981 . 


\section{SUSANA CUARTERO ESCOBÉS}

- finalmente hemos de valorar que aunque la influencia de un arte mayor, como la arquitectura, sobre los sellos es evidente, éstos no tienen importancia en sí mismos como medio de conocimiento de la vida y del pensamiento de quienes los utilizaban $^{33}$.

Tras estas consideraciones más o menos generales, pasamos a describir los anagramas, cuños y sellos de las logias norteamericanas. Seguiremos para ello riguroso orden cronológico y nos limitaremos a las poquísimas ilustraciones que se han conservado ${ }^{34}$. Por este motivo hemos agrupado los sellos escogidos en tres apartados:

- sellos de secretaria;

- sellos personales;

- sellos particulares de cada logia

- Sellos de secretaria: los cuatro que hemos encontrado son muy similares entre sí. En el círculo exterior de los cuatro aparecen dos inscripciones, una en la mitad superior y otra en la mitad inferior, separadas por dos estrellas de cinco puntas.
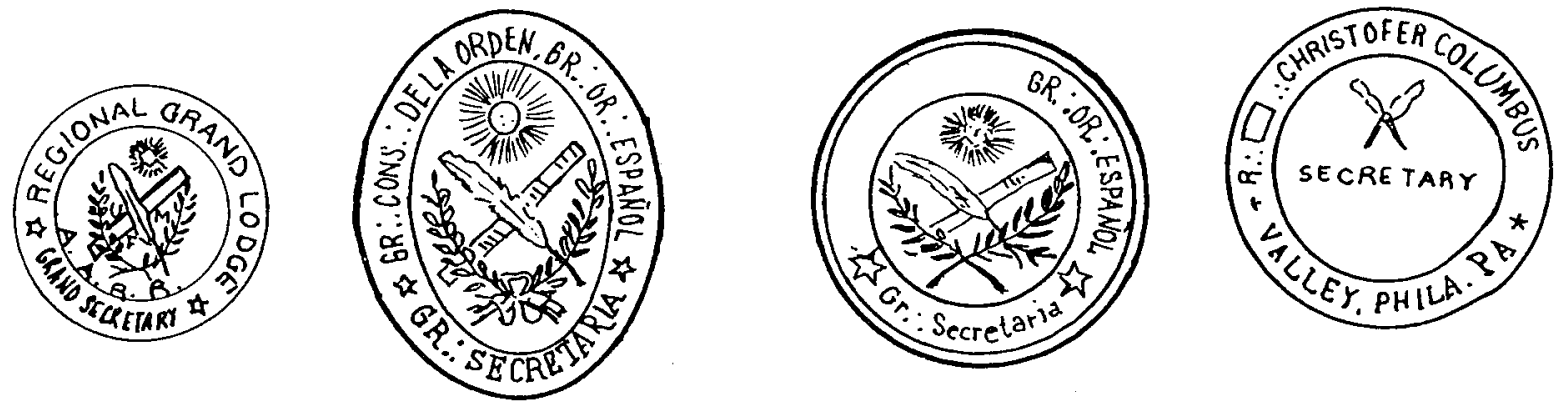

En el interior de los tres primeros figuran los útiles atribuidos al Gran Secretario, pluma y regla cruzadas formando un aspa. Dos ramas de acacia, una a cada lado, ornan el emblema. Encima un sol radiante para iluminar la labor del secretario

En el cuarto los atributos del secretario son algo diferentes: dos plumas cruzadas en lugar de regla y pluma. No existe ningún signo alegórico y aporta poco sobre la iconografía masónica.

En cualquier caso después de observar los cuatro sellos aquí recogidos podemos confirmar que la pluma «es el símbolo más aceptado para representar el cargo de

33 Para esta clasificación nos hemos basado en las consideraciones generales que propone Isabel Alvarez Zamora en «Artes Decorativas», VV. AA. Introducción general al arte, Itsmo, Madrid, 1980.

34 De todos los cuerpos, casi cincuenta logias, tres capítulos y una cámara, que pertenecieron a España, sólo hemos hallado, dispersos por numerosas cartas y documentos, varios, once sellos. De ellos hemos tenido que reproducir casi todos debido al mal estado en el que se encontraban. 
secretaría respondiendo a una tradición secular, en la que se representaba la escritura o bien por medio de un escribiente (recordemos a los evangelistas) o por su forma más simplificada de papel y pluma» ${ }^{35}$.

- Sellos personales: les hemos atribuído este carácter porque en todos figura el nombre de quienes lo utilizaron. En dos aparece el de Harry Goode, en el tercero, el de Albert M. Harley. Ambos fueron grandes dignatarios de la Orden en territorio norteamericano. Lo mismo que en el caso anterior son bastante parecidos entre sí.
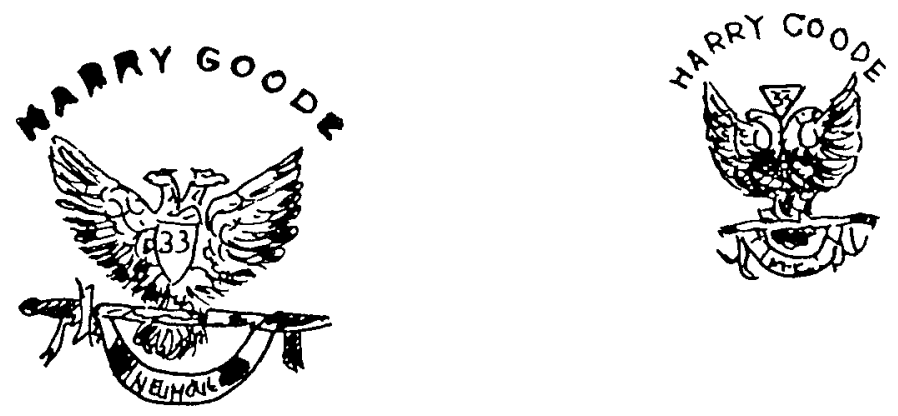

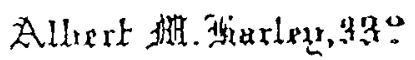

- águila bicéfala como elemento principal. Este emblema es el distintivo de los altos grados de la masonería, los pertenecientes a la denominada masonería filosófica ${ }^{36}$;

- los tres llevan un triángulo en el que figura el grado que tenían, el 33. (Soberano Gran Inspector General);

- en los tres figura el nombre en la parte superior;

- las tres águilas apoyan en la espada flamígera con la banda en la que se lee «Deus Meumque Jus»r.

Las diferencias principales son:

- el lugar de colocación del grado, dos sobre la cabeza y uno en el pecho;

- en el de Albert M. Harley el águila porta una corona real sobre la cabeza. Es más recargado que los de Harry Goode.

35 Muñoz, E. y Ocaña, M. J. «Aproximación a la iconografía y simbología masónica» en Masonería, Revolución y Reacción, Instituto de cultura «Juan Gil-Albert», Zaragoza, 1990, vol.II, p. 885-897.

36 Comprende los grados 31,32 y 33 , también denominados administrativos. 


\section{SUSANA CUARTERO ESCOBÉS}

- Sellos particulares de cada logia: Hemos escogido tan sólo tres para dar una visión lo más amplia posible. Estos son el de la logia Jerusalem nº 247, el del Capitulo Acacia $n^{\circ} 52$ y el de la Gran Logia Regional.
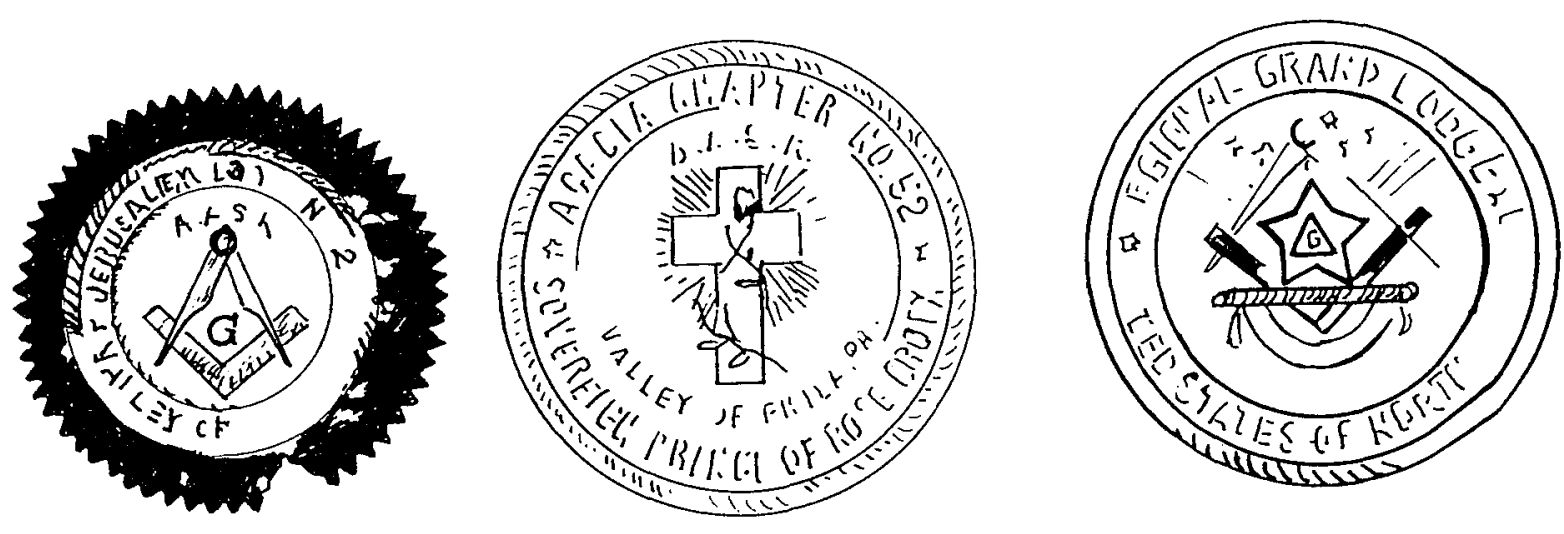

El sello de la logia Jerusalem bastante deteriorado muestra en su centro la letra «G» enmarcada por compás abierto a $45^{\circ}$ sobre escuadra invertida. Este era el símbolo de reconocimiento entre los afiliados libres de las logias de Estrasburgo y otras ciudades alemanas, suizas y francesas de la Edad Media. Encima del compás los restos de las letras A.A.S.R. (Ancient and Accepted Scottish Rite) que era el rito practicado por todas las logias americanas que dependian de España.

Del capítulo Acacia lo primero que salta a la vista es la iconografía, diferente a la de las logias. Esto es lógico si tenemos en cuenta que su origen es diferente al de la masonería operativa, que comprende grados superiores a los de las logias simbólicas y que, por tanto, su simbolismo está imbuido de otros conceptos filosóficos. Una rosa alrededor de una cruz de la que emanan los rayos luminosos, configura el dibujo.

La cruz ha tenido muchos significados a lo largo de la historia. En las antiguas civilizaciones asiáticas y precolombinas, en Egipto, Persia, Grecia... era venerada por diferentes motivos. Para los alquimistas representaba los cuatro elementos generadores de vida: aire, tierra, fuego y agua, mientras que en la tradición cristiana aparece asociada a la idea de muerte.

Por contra la rosa es considerada como la reina de las flores por su belleza y su virtud (esta proviene de la fragancia que desprende). Es, por ello, un símbolo de vida. La imagen completa vendría a representar la regeneración de la vida gracias a la luz divina.

El sello de la Gran Logia Regional es el más complejo. El centro está ocupado por la letra «G» enmarcada en un triángulo que, a su vez, sirve de centro a la estrella. La escuadra invertida y el compás encierran éstos símbolos. Sobre el compás aparece un grupo de estrellas. En la parte inferior, superpuesta a la escuadra, la espada flamígera. De ella pende una banda. Por analogía con otros sellos encontrados debía figurar una leyenda, pero ha sido imposible recuperar su contenido. El fondo del sello está ocupado por los rayos luminosos.

En el círculo exterior, rodeándo el anagrama se lee: Gran Logia Regional. Debajo, Estados Unidos de Norteamérica. El borde es un cordelete. 


\section{SIGILOGRAFIA DE LAS LOGIAS NORTEAMERICANAS}

Membretes y cabeceras de cartas

Figuran en planchas administrativas, cartas y hojas de convocatoria. Su fin es reafirmar la personalidad de cada logia y retener la atención de las otras sobre el anagrama ${ }^{37}$. Las representaciones son más complejas que las de los sellos pero hemos de tener en cuenta que disponen de más espacio. Tomaremos como en el caso anterior sólo tres ejemplos, los más repetidos:

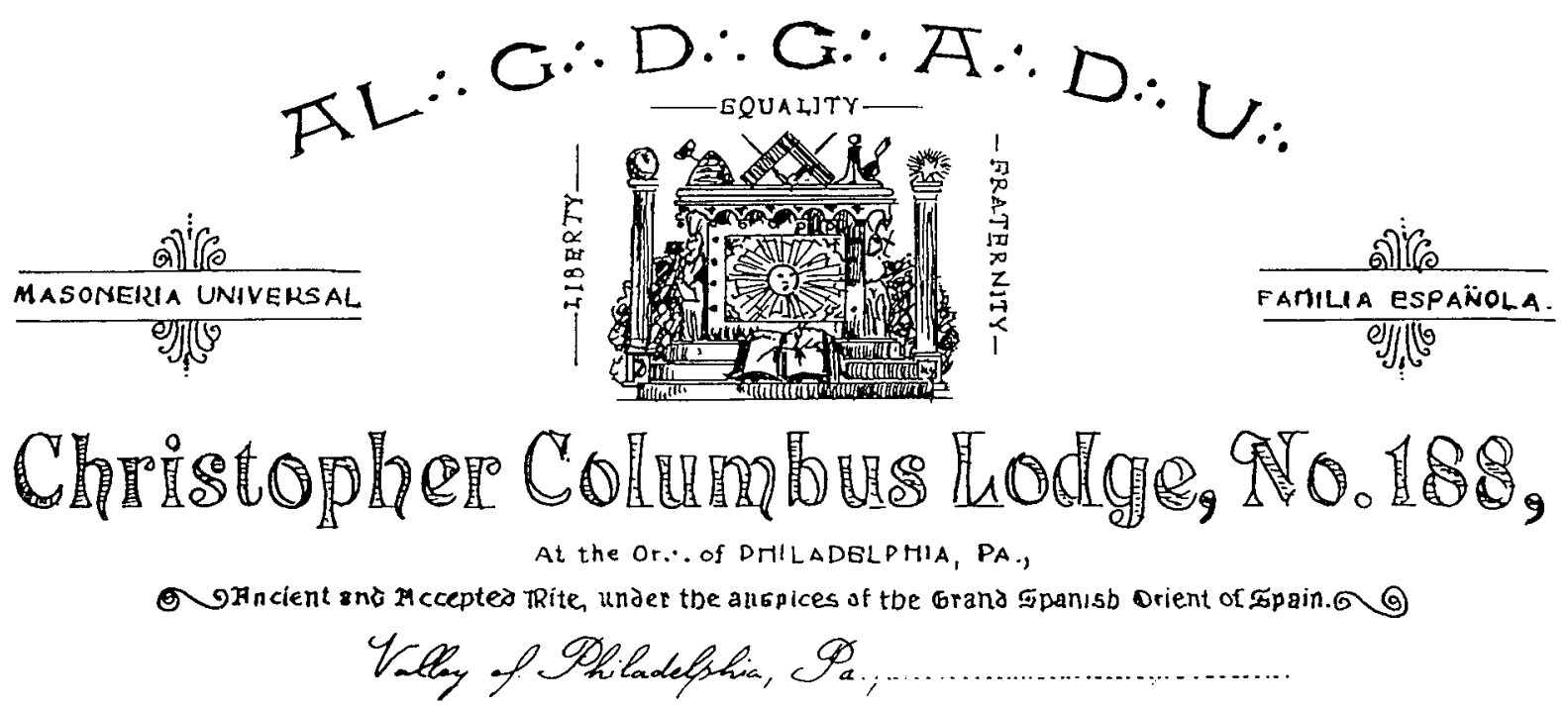

Comienza el membrete con la dedicatoria al Ser a quien dedicaban los trabajos: A La Gloria Del Gran Arquitecto Del Universo. Justo debajo, centrada, una representación resumen de todo el simbolismo masónico, en cierto modo una imagen que evocaría la logia. En primer término, el Libro Sagrado abierto con una rama de acacia encima. Este apoya en la primera de las tres escaleras sobre las que se alza el altar cuyo centro está ocupado por un sol radiante. En la parte superior del altar, la escuadra y el compás invertido. A los lados,el mallete con la piedra bruta y la plomada junto a la paleta o trulla.

Las columnas encierran la imagen. La de la derecha está coronada por la estrella flamígera mientras que en la de la izquierda, una esfera simboliza el universo. Todo ello rodeado por las palabras Libertad Igualdad Fraternidad.

Esta cabecera fue utilizada por las logias Christopher Columbus $n^{\circ} 188$, Delta $n^{\circ} 222$ y Delta $n^{\circ} 294$.

37 Lobreau, D. Franc-Maçonnerie \& Socités..., p. 234. 
SUSANA CUARTERO ESCOBÉS

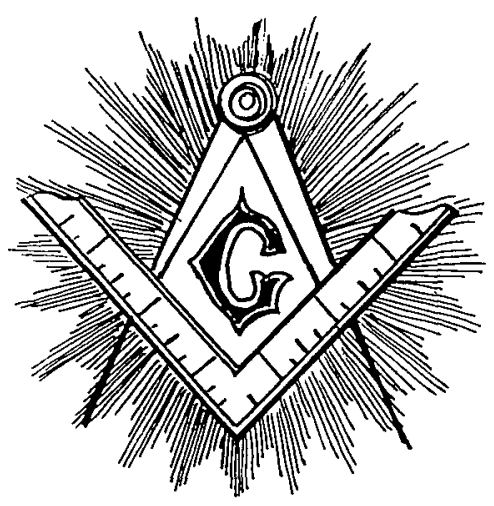

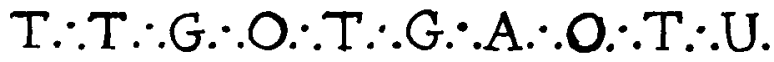 \\ ingisterese

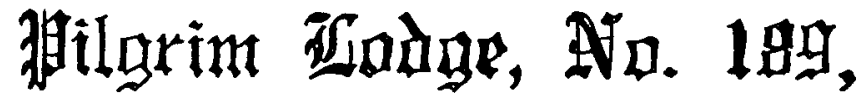

Ancient and Accepled Scottish Rites Universal Free

Masonry. Reqularly Constituled in the Federation

of the Grand Spanish Orient, S. F. U.

Galler of Allentoun, 贍 $1 \mathfrak{L}$

Este otro modelo fue empleado también por varias logias: Pilgrim $n^{\circ}$ 189, San Juan $n^{\circ} 213$ y Fraternity $n^{\circ} 265$. Es mucho más sencillo que el anterior. En el centro del anagrama, escuadra y compás, la letra «G». Todo sobre fondo de rayos luminosos.

Para terminar hemos escogido el membrete que utilizaron los capítulos Evergreen $n^{\circ} 50$ y Acacia no 52. En ellos aparece la simbología completa del grado de Rosa Cruz. Una gran Cruz rematada con corona de príncipe sirve de apoyo a la estrella flamígera. El centro de la misma es otra estrella formada por dos triángulos equiláteros entrelazados. Del centro de la cruz parte el compás cuyo eje es una rosa abierta. Los brazos del compás se ocultan uno tras un águila y otro tras un pelícano. Algunos autores identifican al águila como al ave Phenix.

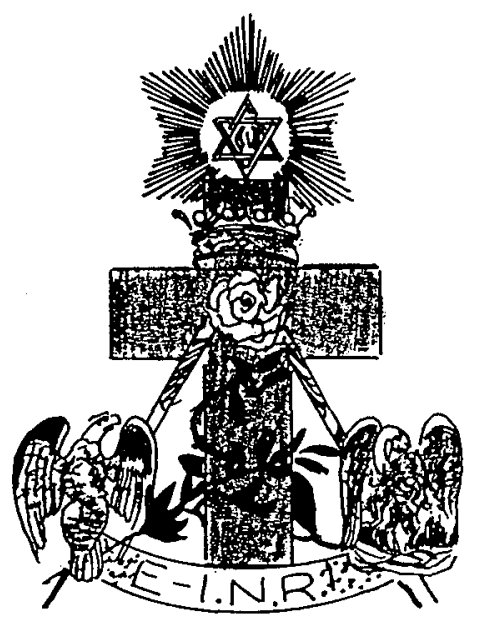

27. R. T. R.

Evergreen Cbapter, Ro. 50

Rose Groir be Ih K. To. So.

rantuersal ffrcemssonry

WALTER T. ALRICW, RLAND P. K. SECY

21 cts of an,

Eraddar Etigints of. $f$.

Qal Pbiladelpbia, pa.,

Al hablar del sello del capítulo Acacia ya explicamos el simbolismo del grado $18^{\circ}$, pero ahora hemos de ampliarlo. En el sello no figuraba el pelícano que sí está aquí. Brevemente 


\section{SIGILOGRAFIA DE LAS LOGIAS NORTEAMERICANAS}

apuntaremos que «simboliza la piedad y es representado de forma heráldica, es decir, de frente con el cuello encorvado, desgarrándose el pecho para alimentar a sus polluelos» 38

Alrededor de la cruz, las ramas de acacia y debajo de ella la banda con la inscripción: I.N.R.I. (Igne Natura Renovatur Integra). El fuego se presenta como elemento generador de vida. La composición es piramidal.

Destacaremos a continuación las letras H.R.D.M. que siguen al título de Rosa Cruz. Son la abreviatura de Heredom o Heredum, palabra que designaría el castillo de San Germanen-Laye, habitado por Carlos Eduardo Estuardo, en el que tenían lugar conciliábulos políticos cuyo fin era atentar contra la república de Inglaterra. ${ }^{39}$. Lo que sí es llamativo es que figuren en este capítulo, pues las letras H.R.D.M. pertenecen a una variante del grado de Rosa Cruz. Esta es la denominada Rosa Cruz de Kilwinning ${ }^{40}$ y de Herodom.

\section{CONCLUSIÓN}

Recapitulando sobre todo lo anterior, la cuestión que nos planteamos es si puede hablarse de un arte propiamente masónico, hecho por y para masones.

Después de todo lo visto hasta aquí, sería casi absurdo negarlo. La masonería nació ligada a los oficios artístico-manuales y nunca dejó de estar relacionada con ellos. Aunque desaparecieron muchos de ellos, las herramientas, los útiles con los que trabajaban perduraron en forma de símbolos y emblemas trasmitidos por tradición. Su significado se fue complicando hasta el punto de que sólo podía accederse a él por medio de un aprendizaje.

Actualmente, hay casi tantas interpretaciones como personas se ocupan del tema. No hay unanimidad de criterios. Todas las opiniones son igual de buenas y de malas, de creíbles y de inverosímiles. Unos interpretan los símbolos a partir de la construcción, otros según la escuela filosófica en la que militan, unos terceros según su ideología, otros a partir del ritual que practican, desde el punto de vista histórico... la lista podía ser interminable.

Lo cierto es que los masones operativos, mediante la construcción, dotaron de espiritualidad sus instrumentos. A partir del siglo XVIII se invierte el orden. Serán esos mismos útiles los que trasmitan la espiritualidad a los hombres.

Por lo que al arte masónico americano respecta, o si se prefiere, a los sellos, diplomas, etc, que hemos analizado, no hay mucho más que añadir. Hay varias muestras más pero aquí sólo hemos podido reflejar una pequeña parte ${ }^{41}$. No existen elementos distintivos americanos en la iconografía utilizada, o sea, que si en la cabecera de una carta por ejemplo, en lugar de poner logia Christopher Columbus $n^{o} 188$, ponen Ibérica $n^{o} 7$ no pasaría nada.

38 Conde Martel, C. «Aspectos simbólicos de los sellos masónicos en Canarias y de la logia Añaza», en Tebeto II, [Anuario del Archivo Histórico Insular de Fuerteventura], 1989, p. 131-176.

39 Frau, L., Diccionario Enciclopédico..., vol. III.

40 Kilwinning era un pequeño caserio situado en la propiedad de William Saint Clair, barón de Roslin, en Escocia. Debe su fama a una antigua torre de bella arquitectura construida por los primeros francmasones.

41 El resto de los sellos y membretes, así como los diplomas y las ilustraciones de los cuadros de oficiales, aparecen en Cuartero, S.: La Masonería española en Estados Unidos (Memoria de Licenciatura inédita). 


\section{SUSANA CUARTERO ESCOBÉS}

Hay una serie de sellos iguales, no la iconografía, que también ocurre, sino la forma geométrica. Ello nos hace pensar que quizá pudo hacerlos la misma persona, la misma fábrica, taller, etc o simplemente, que aprovechaban los mismos moldes y sólo cambiaban parte de la decoración.

Por otra parte, el tamaño de los sellos tampoco nos dice nada de su categoría. En una sociedad profundamente jerarquizada, como era la masonería, podía pensarse que el sello de la Gran Logia tendría que ser de mayor tamaño que el de un capítulo o el de una logia simbólica. Sin embargo, al menos en los que hemos analizado, esto no ocurre.

¿Podrá deberse quizá a que realmente imperaba entre las logia la segunda de las palabras de la famosa trilogia libertad, igualdad y fraternidad...?

Acabemos con una frase del pintor suizo Paul Klee (1879-1940) «El arte no reproduce lo visible, sino que hace visible lo que no siempre es».

Si sustituimos la palabra arte por la palabra símbolo habremos obtenido la definición más acertada de lo que significa la iconografía masónica. 